\title{
Ten Thousand Consecutive Gastrectomies for Gastric Cancer: Perspectives of a Master Surgeon
}

\author{
Yoon Young Choi, Minah Cho, In Gyu Kwon, Taeil Son, Hyoung-Il Kim, \\ Seung Ho Choi, Jae-Ho Cheong, and Woo Jin Hyung \\ Department of Surgery, Yonsei University Health System, Yonsei University College of Medicine, Seoul, Korea.
}

\begin{abstract}
As radical gastrectomy with lymph node dissection is currently the best strategy to cure gastric cancer, the role of the surgeon remains quite important in conquering it. Dr. Sung Hoon Noh, a surgeon and surgical oncologist specializing in gastric cancer, has treated gastric cancer for 30 years and has conducted over 10000 cases of gastrectomy for gastric cancer. He first adapted an electrocautery device into gastric cancer surgery and has led standardization of surgical procedures, including spleen preserving gastrectomy. His procedures based on patient-oriented insights have become the basis of the concept of enhanced recovery after surgery. He has also contributed to improving patient's survival through adoption of a multidisciplinary approach: he proved the benefit of adjuvant chemotherapy after radical D2 gastrectomy for stage II/III gastric cancer in clinical trials, updating treatment guidelines throughout the world. Dr. Noh also opened the era of precision medicine for treating gastric cancer, as he developed and validated a mRNA expression based algorithm to predict prognosis and response to chemotherapy. This article reviews his contribution and long history of service in the field of gastric cancer. The perspectives of this master surgeon, based on his profound experience and insights, will outline directions for integrative multidisciplinary health care and how can surgeons prepare for the future.
\end{abstract}

Key Words: Gastric cancer, surgery, precision medicine, chemotherapy, perspective

\section{INTRODUCTION}

Since the first successful resection for gastric cancer by Theodor Billroth at Vienna General Hospital in 1881, ${ }^{1}$ the treatment of gastric cancer has changed and advanced tremendously. ${ }^{2,3}$ The Department of Surgery, Severance Hospital, Yonsei University College of Medicine, has been at the center of these changes. This institution is one of the largest centers

Received: December 2, 2018

Co-corresponding authors: Jae-Ho Cheong, MD, PhD, Department of Surgery, Yonsei University College of Medicine, 50-1 Yonsei-ro, Seodaemun-gu, Seoul 03722, Korea.

Tel: 82-2-2228-2094, Fax: 82-2-313-8289, E-mail: JHCHEONG @yuhs.ac and

Woo Jin Hyung, MD, PhD, Department of Surgery, Yonsei University College of

Medicine, 50-1 Yonsei-ro, Seodaemun-gu, Seoul 03722, Korea.

Tel: 82-2-2228-2129, Fax: 82-2-313-8289, E-mail: WJHYUNG@yuhs.ac

-The authors have no potential conflicts of interest to disclose.

(C) Copyright: Yonsei University College of Medicine 2019

This is an Open Access article distributed under the terms of the Creative Commons Attribution Non-Commercial License (https://creativecommons.org/licenses/ by-nc/4.0) which permits unrestricted non-commercial use, distribution, and reproduction in any medium, provided the original work is properly cited. in the world specializing in gastric cancer treatment, and surgeons at the hospital perform surgeries on high-risk patients. ${ }^{4,5}$ The most recent practices include new techniques, such as laparoscopic and robotic surgery ${ }^{6-10}$ Not necessarily limited to patient care delivery, the surgeons at this institution have been leading translational research in the field of gastric cancer, ${ }^{11-17}$ with the advantage of a high volume of surgical cases (over 1200 gastrectomies annually).

Dr. Sung Hoon Noh is a distinguished gastric cancer surgeon and a surgical oncologist. He is the head of the Gastric Cancer Clinic team at Severance Hospital, and his valuable contributions to the field of gastric cancer are important and meaningful. As a clinician, he performed his 10000th gastrectomy for gastric cancer on November 7th, 2017. As an academic surgeon, he has published more than 350 scientific papers. As a mentor, he has overseen the training of numerous international and domestic surgical fellows and residents, and has dedicated his career to bettering the understanding of gastric cancer and surgical oncology. He has also served in various positions in academic societies as a key opinion leader in the community. This article reviews his profound contribu- 
tions and long history of service in the field of gastric cancer, including his 10000 consecutive gastric cancer surgeries, and provides perspectives from his experience. As his contributions to the field of gastric cancer are extensive, this review will surely omit achievements of Dr. Sung Hoon Noh that some of his colleagues consider very important. We wish the readers will be generous on any omissions.

\section{RÉSUMÉ OF DR. NOH}

Dr. Sung Hoon Noh has worked at Severance Hospital since 1987. He was the 16th Chairman of the Department of Surgery, Yonsei University College of Medicine (2009-2013), and Director of the Yonsei Cancer Center (2008-2009, 2013-2019). He has been a Fellow of the American College of Surgeons since 2008. He has served as the President of the Korean Gastric Cancer Association (2009-2011) and International Gastric Cancer Association (2011-2013); the Vice President of the Korean Society of Gastroenterology (2011-2012), the Chairman of the Board of the Korean Cancer Association (2011-2013), and the Chairman of the Board (2014-2018); and President of the Korean Surgical Society (2018-2019). He is a member of the National Academy of Medicine of Korea and the Korean Academy of Science Technology.

\section{REVIEW OF THE 10000 GASTRECTOMIES FOR GASTRIC CANCER PERFORMED BY DR. NOH}

Dr. Noh performed his first gastrectomy for gastric cancer in 1987, and has performed 10000 gastrectomies for gastric can- cer as of November 7, 2017: his annual number of gastrectomies was over 600 at his peak (Fig. 1). The mean age of his patients was 56.9-years, with 6607 and 3393 male and female patients, respectively. He performed 6978 distal subtotal gastrectomies and 3022 total gastrectomies, including completion total gastrectomy. He treated all stages of gastric cancer, of which $50.1,17.3,27.8$, and $4.5 \%$ were pathologic stages I, II,

Table 1. Summary of 10000 Gastrectomies Dr. Noh Performed

\begin{tabular}{|c|c|}
\hline Variables & Number (\%) / Mean \pm SD \\
\hline Age (yr) & $56.9 \pm 11.8$ \\
\hline \multicolumn{2}{|l|}{ Sex, $n(\%)$} \\
\hline Male & $6607(66.1)$ \\
\hline Female & 3393 (33.9) \\
\hline \multicolumn{2}{|l|}{ Extent of gastrectomy, $\mathrm{n}(\%)$} \\
\hline STG & $6978(69.8)$ \\
\hline TG & 3022 (30.2) \\
\hline Size (mm) & $43.5 \pm 30.2$ \\
\hline Number of harvested LNs & $42.3 \pm 15.9$ \\
\hline Hospital stays (days) & $11.5 \pm 8.3$ \\
\hline Operation time $(\mathrm{min})^{*}$ & $190.1 \pm 44.8$ \\
\hline \multicolumn{2}{|l|}{ Stage, n (\%) } \\
\hline I & $5012(50.1)$ \\
\hline$\|$ & $1725(17.3)$ \\
\hline III & $2777(27.8)$ \\
\hline IV & $446(4.5)$ \\
\hline NOS & $40(0.4)$ \\
\hline \multicolumn{2}{|l|}{ Mortality, n (\%) } \\
\hline 30 days & $31(0.31)$ \\
\hline 60 days $^{\dagger}$ & $69(0.69)$ \\
\hline
\end{tabular}

STG, subtotal gastrectomy; TG, total gastrectomy including completion total gastrectomy; LN, lymph node; NOS, not otherwise specified.

*Including time for anesthesia, ${ }^{\dagger}$ Including 30 days mortality.

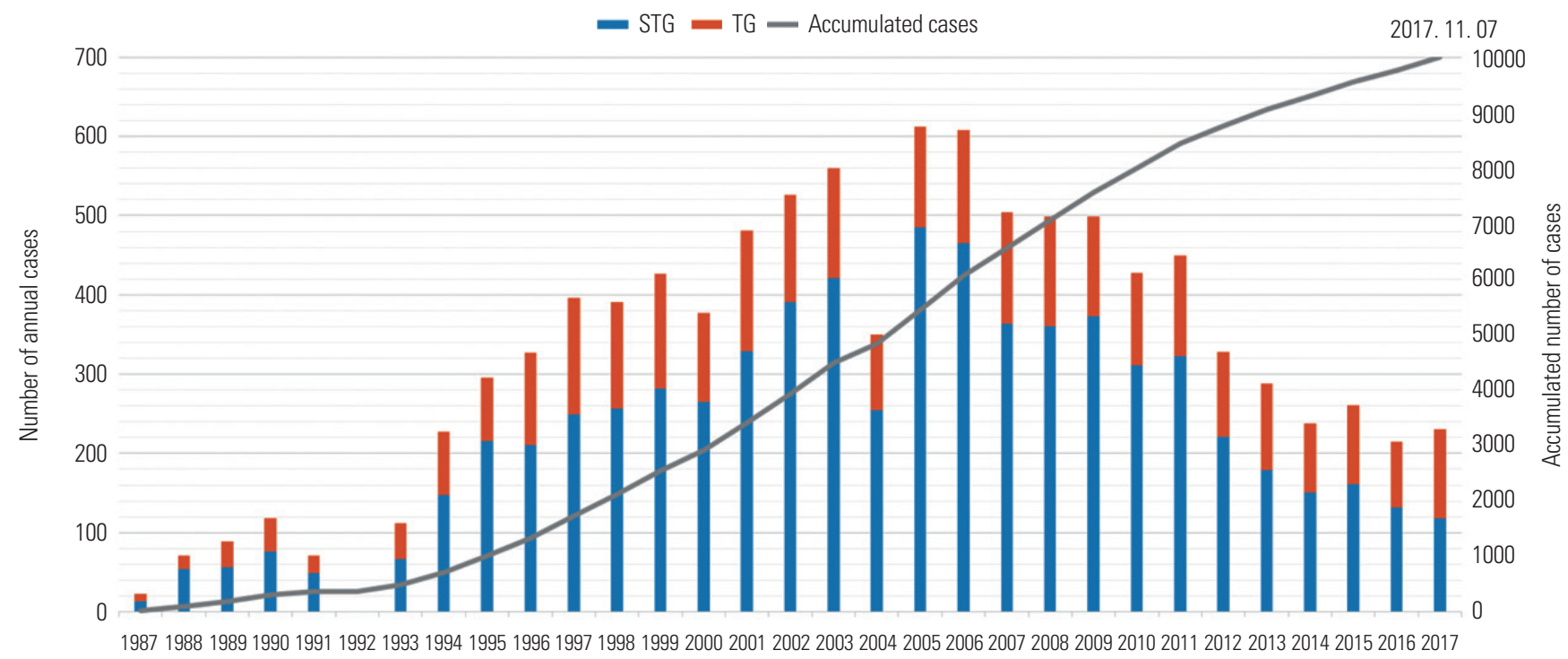

Fig. 1. Annual number of gastrectomy cases performed by Dr. Noh. STG, subtotal gastrectomy; TG, total gastrectomy including completion total gastrectomy. 
III, and IV, respectively (Table 1). His mean operative time was 190.1 minutes, including time for anesthesia; the mean hospital stay was 11.5 days; and there were 31 cases $(0.31 \%)$ of surgical mortality within 30 days.

\section{DEVELOPMENT AND STANDARDIZATION OF SURGICAL TECHNIQUES FOR GASTRIC CANCER}

Dr. Noh first used an electrocautery device, "Bovie" for lymph node dissection in gastric cancer surgery in 1989. His use of the Bovie device for procedures in gastric cancer surgery increased over time, and he ultimately used the Bovie throughout the entire procedure. He first presented an operative video of gastric cancer surgery using the Bovie in 1995 at the Congress of the Korean Surgical Society. As this technique is now common, most young surgeons may not recognize the importance of this challenge; moreover, many senior surgeons criticized his use of the Bovie due to concerns for thermal injury to the bowel and blood vessels. He persevered and advanced this procedure and presented another operative video in 1996 on radical gastrectomy with $\mathrm{D} 2$ lymph node dissection for advanced gastric cancer using the Bovie at the Congress of the International Association of Surgeons, Gastroenterologists, and Oncologists. This procedure subsequently attracted international attention among surgeons.

Next, he expanded the application of the Bovie to spleenpreserving total gastrectomy. Historically, pancreatico-splenectomy was a standard procedure in radical total gastrectomy for gastric cancer because the extent of lymph node dissection includes supra-pancreatic and splenic hilar areas. In 1979, Dr. Maruyama developed pancreas preserving total gastrectomy. In 1995, he reported that pancreas-preserving total gastrectomy, compared to conventional total gastrectomy with distal pancreatectomy, had low morbidity and mortality with similar oncologic outcomes, and total gastrectomy with splenectomy subsequently became a standard procedure. ${ }^{18}$ Dr. Noh questioned the necessity of splenectomy for total gastrectomy and introduced spleen-preserving total gastrectomy with D2 lymph node dissection (including splenic hilar lymph node dissection). He presented a video of this procedure using the Bovie in 1997 at the 2nd International Gastric Cancer Congress. ${ }^{19,20}$ Because this procedure was considered technically very difficult, its feasibility impressed other surgeons, many of whom, including gastric cancer experts, came to Yonsei University to observe Dr. Noh's technique. His clinical data showed that spleen preservation during total gastrectomy is associated with low morbidity and similar or better survival outcomes compared to those of total gastrectomy with splenectomy. ${ }^{21,22}$ Subsequent studies including a randomized controlled trial supported his results, ${ }^{23,24}$ and spleen preservation is now a standard procedure for total gastrectomy. He also developed new surgical techniques that can reduce anastomosis leakage after gastroduodenostomy. ${ }^{25,26}$

Dr. Noh has sought to improve survival in gastric cancer with peritoneal metastases. He first used cyto-reductive surgery with intraperitoneal chemotherapy for gastric cancer in Korea in 1993, ${ }^{27-29}$ followed by hyperthermic intraperitoneal chemotherapy (HIPEC) in 1995. These intraperitoneal treatments for recurrent gastric cancer have been revisited as chemotherapy regimens have evolved, and HIPEC, extensive peritoneal lavage, ${ }^{30}$ and most recently, pressurized intraperitoneal aerosol chemotherapy ${ }^{31}$ have been attempted and evaluated for efficacy in gastric cancer.

He has always emphasized the importance of oncologic principles in gastric cancer surgery to his fellows and residents. The "no-touch technique," in which the tumor is wrapped with surgical tape or towels to prevent contamination of the surgeon's hands and dissemination in the surgical field and patient's abdomen, is a key principle in gastric cancer surgery. Minimizing manipulation of the stomach to reduce dissemination of tumor cells through blood and lymphatic vessels, anatomical and meticulous dissection with careful hemostasis to prevent direct spillage of tumor cells, and en-bloc lymphadenectomy with complete surgical resection of macro/microscopic tumors (R0) are also basic and important principles in gastric cancer surgery.

\section{PROCEDURAL CHANGES BASED ON PATIENT-ORIENTED INSIGHTS}

Dr. Noh was interested in reducing discomfort in patients undergoing surgery for gastric cancer. Believing that the patient is the most important part of the medical team, he was deeply concerned for frequent complaints of postoperative pain from the incision, nasogastric tube, and drainage tube. To relieve pain, he introduced the epidural patient-controlled analgesia pump in the clinic in 1997. He also demonstrated the feasibility of gastric cancer surgery with a $<15-\mathrm{cm}$ midline incision to reduce postoperative pain. In addition, to minimize surgical stress, he reduced operative time and blood loss, as well as the need for transfusion through his use of the Bovie.

Nasogastric tube insertion was for a long time a standard procedure for most gastrointestinal surgeries, with the belief that it could reduce postoperative anastomosis leakage and decompress bowel gas. He questioned this belief and conducted a single-center randomized controlled trial to compare clinical outcomes with and without nasogastric tube insertion for gastric cancer surgery and found no difference between the procedures. ${ }^{32}$ Accordingly, he discontinued routine nasogastric tube use for gastric cancer surgery in his clinic. To achieve a good operative field during surgery, he developed a simple technique to decompress the stomach and colon without the use of a nasogastric tube. ${ }^{33,34}$ 
Dr. Noh also evaluated the necessity of routine intraperitoneal drainage for gastric cancer surgery and found no difference in short-term outcomes with or without use of a drainage tube. ${ }^{35}$ As his experience without using a drainage tube accumulated, he found that postoperative external drainage is required for some patients. He therefore developed a predictive model to identify high-risk patients who would require postoperative drainage, ${ }^{36}$ enabling selective insertion of a drainage tube in gastric cancer surgery. His collective efforts were the basis for the concept of enhanced recovery after surgery.

\section{IMPROVING SURVIVAL IN GASTRIC CANCER THROUGH A MULTIDISCI- PLINARY APPROACH}

After a trial comparing the clinical outcomes of D2 versus D2 + para-aortic lymph node dissection failed to show the benefit of D4 lymph node dissection, ${ }^{37}$ the optimal extent of radical lymph node dissection was considered D2 level. ${ }^{38-40}$ As techniques became standardized and postoperative management evolved, the benefit of radical surgery to survival in gastric cancer had reached a maximum. To improve survival in gastric cancer, another strategy, such as chemotherapy or radiation therapy, was needed; however, until 2001, it was thought that surgery was the only effective treatment option for resectable gastric cancer. ${ }^{41}$ The success of the Intergroup and MAGIC trials ${ }^{42,43}$ showed the benefit of perioperative chemotherapy and postoperative chemotherapy combined with radiation therapy compared to surgery alone, leading to the era of adjuvant/neoadjuvant therapy for resectable gastric cancer. However, the trials were criticized because radical surgery with D2 lymph node dissection was only performed in some of the patients; furthermore, the prognosis of those who received additional treatment plus surgery was much worse than in patients who received radical surgery alone in Korea.

To evaluate the benefit of adjuvant chemotherapy after radical D2 surgery for gastric cancer, Dr. Noh and Dr. Yung-Jue Bang designed and conducted the Capecitabine and Oxaliplatin Adjuvant Study in Stomach Cancer (CLASSIC) trial targeting stage II/III gastric cancer. Thirty-seven institutions from Korea, China, and Taiwan participated in this open-label, parallel-group, phase III, prospective randomized controlled trial. This trial succeeded in showing the clear survival benefit of adjuvant chemotherapy after D2 surgery, compared to D2 surgery alone. ${ }^{44,45}$ This result changed clinical practice from a D2 surgery alone strategy to D2 surgery plus adjuvant chemotherapy and contributed to improvement in survival in gastric cancer. These results were included in international guidelines for treatment of gastric cancer. ${ }^{40,46,47}$

Another phase III, open-label, randomized controlled trial, PRODIGY, has been designed by Dr. Noh and Dr. Yoon-Koo Kang to determine whether early administration of chemo- therapy in addition to conventional adjuvant chemotherapy would improve survival in gastric cancer (NCT01515748). In this study, the effect of Neoadjuvant Docetaxel+Oxaliplatin+ S-1 (DOS)+Surgery+adjuvant S-1 compared to Surgery+adjuvant S-1 in patients with resectable advanced gastric cancer has been investigated. Enrollment in this trial has been completed and the final results will be announced soon. The trial is expected to provide another treatment option for patients with gastric cancer.

\section{INTRODUCTION OF PRECISION MEDICINE FOR TREATMENT OF GASTRIC CANCER}

Despite the success of the CLASSIC trial, there remains a number of unmet clinical needs in the treatment of gastric cancer. Most of all, few clinically applicable biomarkers have been identified for use in stratifying patients with resectable gastric cancer according to prognosis and/or response to chemotherapy. Given that more than approximately $60 \%$ of patients do not seem to benefit from adjuvant chemotherapy after curative intent D2 surgery, development of clinically usable biomarkers to identify these subgroup of patients is an urgent need in real-world clinic. According to the final result of the CLASSIC trial, estimated 5-year disease-free survival was $68 \%$ and $53 \%$ in the D2 surgery plus adjuvant chemotherapy group and D2 surgery only group, respectively. ${ }^{44,45}$ The $15 \%$ added benefit was clinically valuable and suggested that half of patients with stage II/III gastric cancer can be treated with D2 surgery alone; however, only $15 \%$ of those treated with adjuvant chemotherapy received real benefit from chemotherapy, which caused treatment-related toxicity. If we can predict who will be cured with surgery alone without use of adjuvant chemotherapy, a significant number of patients can avoid unnecessary medication-induced toxicity. Moreover, if we can predict who will benefit from adjuvant chemotherapy, we can select patients for treatment using a current standard regimen or a regimen other than standard chemotherapy. In the middle of the CLASSIC trial, Dr. Noh realized the need for a biomarker study.

One possible biomarker is microsatellite instability (MSI). The clinical characteristics of MSI-high (MSI-H) colorectal cancer have been well studied; MSI-H tumors show good prognosis and are not responsive to 5-fluorouracil-based chemotherapy. ${ }^{48}$ Consequently, guidelines recommend consideration of MSI status in colorectal cancer in deciding whether to use adjuvant chemotherapy. ${ }^{49}$ Dr. Noh and his colleagues conducted a meta-analysis and retrospective cohort studies to evaluate the clinical implications of MSI-H status in gastric cancer. As in colorectal cancer, MSI-H gastric cancer has a good prognosis, although the benefit from adjuvant chemotherapy in stage II/III gastric cancer was not clear. ${ }^{11,50,51}$ These 
results were validated in randomized controlled trial cohorts in the CLASSIC and MAGIC studies. ${ }^{12,52,53}$ Accordingly, MSI status has been deemed a powerful candidate biomarker that can be used in clinical practice, and treatment guidelines are likely to recommend its use in deciding treatment with or without chemotherapy for stage II/III gastric cancer.

Some trials have classified various tumors according to molecular characteristics, ${ }^{54,55}$ some of which can be applied in clinical practice to predict responsiveness to chemotherapy. ${ }^{56,57}$ Some molecular subtypes of gastric cancer have been evaluated according to genetic characteristics, including mRNA expression levels ${ }^{58-60}$; however, the clinical implications were not clear or validated. Dr. Noh and his colleagues conducted a meta-analysis on mRNA expression data using multiple gastric cancer cohorts, including those from the Yonsei cohort, and found that gastric cancer can be stratified into five molecular subtypes based on the expression patterns of tu-
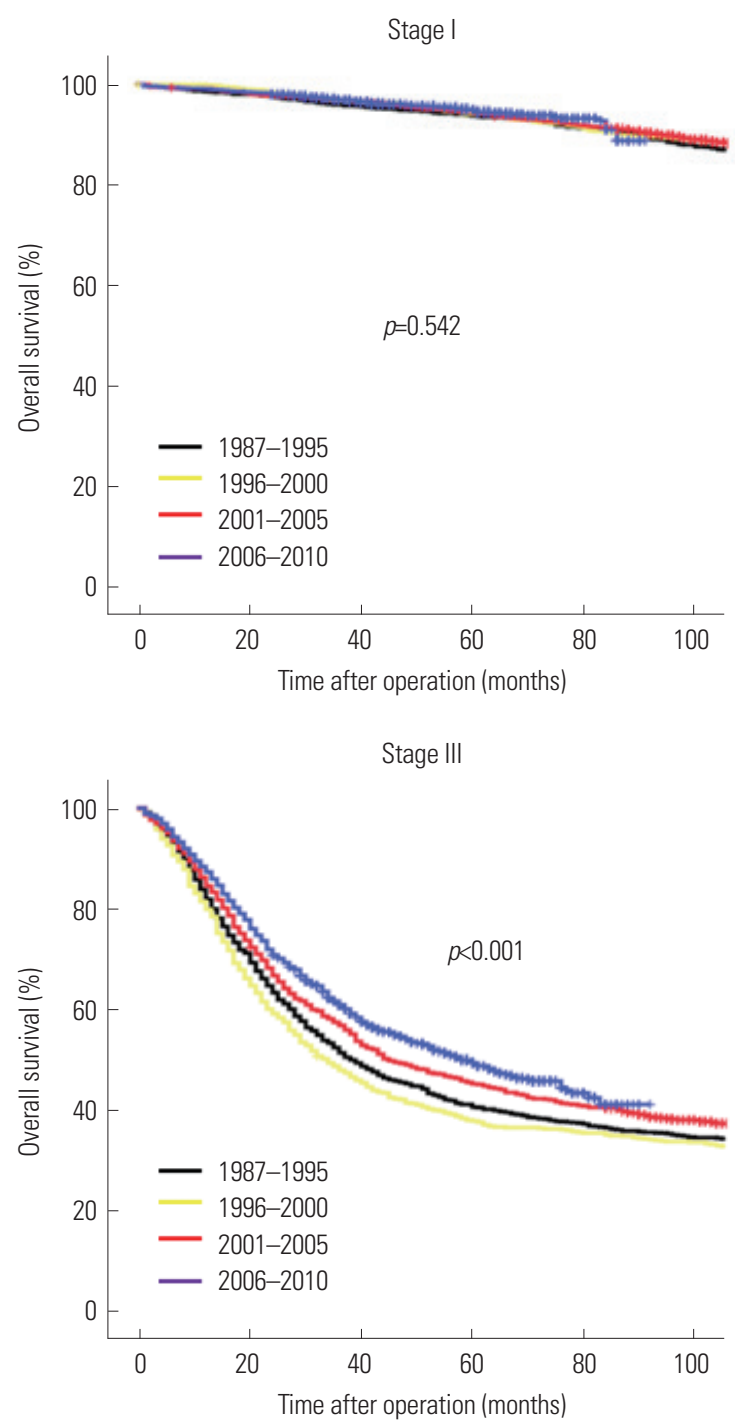

mor transcriptome. Through rigorous statistical analyses, they identified four genes (with mRNA expression of five housekeeping genes), based on a single patient classifier (SPC) algorithm. According to the SPC algorithm, an immune type with enriched immune signatures (GZMB- and WARS-positive) was associated with a good prognosis, but was not responsive to adjuvant chemotherapy. Cancers with high expression of cancer stem-cell (ST type)-related gene (SFRP4) were associated with the worst prognosis. If cancer exhibits high expression of epithelial cell-related gene (CDX1, EP type), the benefit from adjuvant chemotherapy is obvious; however, a tumor with low expression of $C D X 1$ is likely to receive no additional benefit from chemotherapy, compared to surgery alone. These results were validated in the CLASSIC trial cohort; ${ }^{14}$ consequently, the SPC algorithm was implemented in clinical practice to stratify patients with gastric cancer according to whether or not adjuvant chemotherapy should
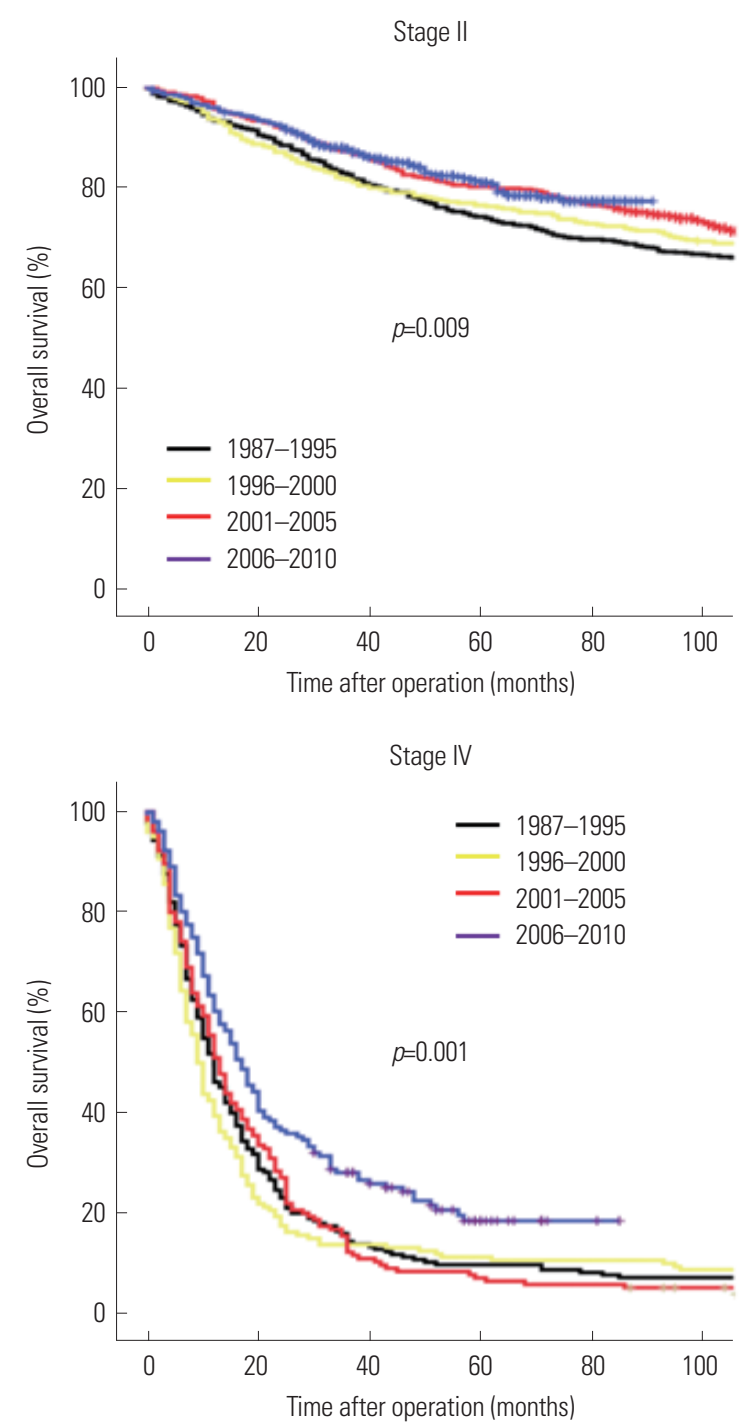

Fig. 2. Changes in overall survival for patients with gastric cancer treated at Yonsei Gastric Cancer Center according to stage (AJCC 7th) and time. AJCC, American Joint Committee on Cancer. 
be given after surgery. Dr. Noh's collective efforts and achievements have ushered in the era of precision medicine for treatment of resectable gastric cancer. ${ }^{61}$

\section{OTHER CONTRIBUTIONS}

Dr. Noh planed establishing a clinical database in the Yonsei Gastric Cancer Clinic in 1993, and the first version was completed in 1998. This database made it possible to evaluate and respond to many clinical questions concerning gastric cancer, with the results leading to changes in treatment. Dr. Noh organized the Yonsei Gastric Cancer Symposium in 2000; this symposium was the first gastric cancer-specific conference in Korea, and the first to show live surgery in a symposium. The Yonsei Gastric Cancer Symposium has become an annual international event and has contributed to the dissemination of knowledge about gastric cancer surgery, including technical tips, treatment, biology, and translational research. Dr. Noh has also performed live surgeries in many countries to promote the excellence of gastric cancer treatment in Yonsei and Korea. Many surgeons from other countries including Japan visit Korea to learn about surgery for gastric cancer. To educate doctors who cannot visit Korea, he has organized live web seminars and for internet study. The efforts by Dr. Noh have led to progressively improved survival of patients with gastric cancer at Yonsei (Fig. 2).

\section{PERSPECTIVES OF A MASTER SURGEON}

Although major practice changes and scientific developments have occurred over the last decades, continued innovation is necessary to curb the burden of gastric cancer. New screening systems targeting high-risk individuals based on genomic characteristics should be developed for super-early detection of gastric cancer. How we manage the rapid increase in survivors of gastric cancer and the occurrence of a second malignancy should be considered. Since the extent of lymph node dissection for advanced gastric cancer is set at D2 level, current surgery is somewhat standardized rather than personalized. Improving our knowledge of cancer biology will enable us to predict lymph node metastasis before surgery, and advances in technology for intraoperative visualization of lymph nodes $^{6}$ will make it possible to perform tailored surgery. Consequently, the roles of limited and minimally invasive surgery including endoscopic resection and robot-assisted surgery will expand. Combined targeted therapy and immunotherapy based on molecular characteristics if individual tumors will be accepted, and the treatment of patients can be tailored in greater detail as the concept of the $\mathrm{N}$-of-one trial being realized, leading to personalized treatment. Although surgery has not seemed helpful in patients with distant metastases, ${ }^{62}$ we will be able to identify subgroups in which surgery can cure the disease, as some of these patients will demonstrate longterm survival. ${ }^{63}$ Future changes will be based on not only the molecular characteristics of tumor itself but also those of the patients, and the importance of a multi-disciplinary approach will be further emphasized. Clinician-based Multi-Disciplinary Treatment will and should evolve to Integrative Multi-Disciplinary Health Care that includes not only clinicians but also basic scientists, ancillary providers, and even patients and their families. At the center of these changes, surgeons should spearhead paving the road and taking legitimate leadership. This requires understanding of the biology of cancer and active involvement in clinical, translational, and basic research. We are now in an era of precision health care beyond precision surgery.

\section{ACKNOWLEDGEMENTS}

Dr. Sung Hoon Noh dedicates this review to his family, especially to his lovely, but now deceased wife Mrs. Young Soon Lee. He expresses gratitude to his senior mentors, Dr. Jin Sik Min and Dr. Kyung Sik Lee, who inspired him to be a great surgeon. He also thanks all of his colleagues including Dr. Choong Bae Kim and fellows (Dr. Chang-hak Yoo, Yong Il Kim, Dong-woo Shin, Ki-hyeok Lah, Junho Lee, Changsoo Song, Sungsoo Kim, Sung Jin Oh, Ji Yeong An, Jong Won Kim, Seongguen Hwang, Geon-Ung Heo, Seokho Yoon, Kyung Ho Park, Jyewon Song, Joong Ho Lee, Yoo-Min Kim, In Cho, Hyun Beak Shin, Sang Hyuk Seo, Hui-Jae Bang, Seung Hyun Lim, You-Na Kim, Kun Ho Roh, Chul Kyu Roh, Won Jun Seo, Seohee Choi) and foreign fellows in the Department of Surgery and the Yonsei Gastric Cancer Center who have treated and studied gastric cancer with him. He also deeply appreciates the patients and families who have entrusted their lives to his care.

We thank Dr. Jung-Won Park, Editor-in-Chief of the Yonsei Medical Journal, for accepting this memorable perspective and history of Dr. Noh for publication.

\section{AUTHOR CONTRIBUTIONS}

Conceptualization: Yoon Young Choi, Jae-Ho Cheong, Woo Jin Hyung. Data curation: Yoon Young Choi, Minah Cho, In Gyu Kwon, Taeil Son, Hyoung-Il Kim, Seung Ho Choi, Jae-Ho Cheong, Woo Jin Hyung. Formal analysis: Yoon Young Choi. Funding acquisition: JaeHo Cheong, Woo Jin Hyung. Investigation: Yoon Young Choi, Minah Cho, In Gyu Kwon, Taeil Son, Hyoung-Il Kim, Seung Ho Choi, Jae-Ho Cheong, Woo Jin Hyung. Methodology: Yoon Young Choi, Jae-Ho Cheong, Woo Jin Hyung. Project administration: Jae-Ho Cheong, Woo Jin Hyung. Resources: Yoon Young Choi, Minah Cho, In Gyu Kwon, Taeil Son, Hyoung-Il Kim, Seung Ho Choi, Jae-Ho Cheong, Woo Jin Hyung. Software: Yoon Young Choi, Minah Cho, In Gyu Kwon, Taeil Son, Hyoung-Il Kim, Seung Ho Choi, Jae-Ho Cheong, Woo Jin Hyung. Supervision: Jae-Ho Cheong, Woo Jin Hyung. Validation: Yoon Young Choi, Minah Cho, In Gyu Kwon, Taeil Son, Hyoung- 
Il Kim, Seung Ho Choi, Jae-Ho Cheong, Woo Jin Hyung. Visualization: Yoon Young Choi. Writing-original draft: Yoon Young Choi. Writing - review \& editing: Jae-Ho Cheong, Woo Jin Hyung.

\section{ORCID iDs}

$\begin{array}{ll}\text { Yoon Young Choi } & \text { https://orcid.org/0000-0002-2179-7851 } \\ \text { Minah Cho } & \text { https://orcid.org/0000-0003-3011-5813 } \\ \text { In Gyu Kwon } & \text { https://orcid.org/0000-0002-1489-467X } \\ \text { Taeil Son } & \text { https://orcid.org/0000-0002-0327-5224 } \\ \text { Hyoung-Il Kim } & \text { https://orcid.org/0000-0002-6134-4523 } \\ \text { Seung Ho Choi } & \text { https://orcid.org/0000-0002-9872-3594 } \\ \text { Jae-Ho Cheong } & \text { https://orcid.org/0000-0002-1703-1781 } \\ \text { Woo Jin Hyung } & \text { https://orcid.org/0000-0002-8593-9214 }\end{array}$

\section{REFERENCES}

1. Billroth T. [Offenes schreiben an Herrn Dr. L. Wittelshofer]. Wien Med Wochenschr 1881;31:161-5.

2. Choi YY, Cheong JH. Beyond precision surgery: molecularly motivated precision care for gastric cancer. Eur J Surg Oncol 2017; 43:856-64.

3. Choi YY, Noh SH, Cheong JH. Molecular dimensions of gastric cancer: translational and clinical perspectives. J Pathol Transl Med 2016;50:1-9.

4. Kwon IG, Cho I, Guner A, Kim HI, Noh SH, Hyung WJ. Minimally invasive surgery as a treatment option for gastric cancer in the elderly: comparison with open surgery for patients 80 years and older. Surg Endosc 2015;29:2321-30.

5. Kwon IG, Cho I, Choi YY, Hyung WJ, Kim CB, Noh SH. Risk factors for complications during surgical treatment of remnant gastric cancer. Gastric Cancer 2015;18:390-6.

6. Kwon IG, Son T, Kim HI, Hyung WJ. Fluorescent lymphographyguided lymphadenectomy during robotic radical gastrectomy for gastric cancer. JAMA Surg 2018 Nov 14 [Epub]. Available at: https://doi.org/10.1001/jamasurg.2018.4267.

7. Seo WJ, Son T, Roh CK, Cho M, Kim HI, Hyung WJ. Reduced-port totally robotic distal subtotal gastrectomy with lymph node dissection for gastric cancer: a modified technique using Single-Site ${ }^{\circledR}$ and two additional ports. Surg Endosc 2018;32:3713-9.

8. Woo Y, Goldner B, Son T, Song K, Noh SH, Fong Y, et al. Western validation of a novel gastric cancer prognosis prediction model in US gastric cancer patients. J Am Coll Surg 2018;226:252-8.

9. Lee JH, Tanaka E, Woo Y, Ali G, Son T, Kim HI, et al. Advanced real-time multi-display educational system (ARMES): an innovative real-time audiovisual mentoring tool for complex robotic surgery. J Surg Oncol 2017;116:894-7.

10. Obama K, Kim YM, Kang DR, Son T, Kim HI, Noh SH, et al. Longterm oncologic outcomes of robotic gastrectomy for gastric cancer compared with laparoscopic gastrectomy. Gastric Cancer 2018;21: 285-95.

11. Choi YY, Bae JM, An JY, Kwon IG, Cho I, Shin HB, et al. Is microsatellite instability a prognostic marker in gastric cancer? A systematic review with meta-analysis. J Surg Oncol 2014;110:129-35.

12. Choi YY, Kim H, Shin SJ, Kim HY, Lee J, Yang HK, et al. Microsatellite instability and programmed cell death-ligand 1 expression in stage II/III gastric cancer: post hoc analysis of the CLASSIC randomized controlled study. Ann Surg 2018 May 1 [Epub]. Available at: https://doi.org/10.1097/SLA.0000000000002803.

13. Lee J, Kim H, Lee JE, Shin SJ, Oh S, Kwon G, et al. Selective cytotoxicity of the NAMPT inhibitor FK866 toward gastric cancer cells with markers of the epithelial-mesenchymal transition, due to loss of NAPRT. Gastroenterology 2018;155:799-814.

14. Cheong JH, Yang HK, Kim H, Kim WH, Kim YW, Kook MC, et al. Predictive test for chemotherapy response in resectable gastric cancer: a multi-cohort, retrospective analysis. Lancet Oncol 2018; 19:629-38.

15. Park KC, Kim SW, Jeon JY, Jo AR, Choi HJ, Kim J, et al. Survival of cancer stem-like cells under metabolic stress via CaMK2 $\alpha$ mediated upregulation of sarco/endoplasmic reticulum calcium ATPase expression. Clin Cancer Res 2018;24:1677-90.

16. Roh CK, Choi YY, Choi S, Seo WJ, Cho M, Jang E, et al. Single patient classifier assay, microsatellite instability, and Epstein-Barr virus status predict clinical outcomes in stage II/III gastric cancer: results from CLASSIC trial. Yonsei Med J 2019;60:132-9.

17. Choi YY, Jang E, Seo WJ, Son T, Kim HI, Kim H, et al. Modification of the TNM staging system for stage II/III gastric cancer based on a prognostic single patient classifier algorithm. J Gastric Cancer 2018;18:142-51.

18. Maruyama K, Sasako M, Kinoshita T, Sano T, Katai H, Okajima K. Pancreas-preserving total gastrectomy for proximal gastric cancer. World J Surg 1995;19:532-6.

19. Choi YY, Noh SH, Cheong JH. Evolution of gastric cancer treatment: from the golden age of surgery to an era of precision medicine. Yonsei Med J 2015;56:1177-85.

20. Choi YY, An JY, Kim HI, Cheong JH, Hyung WJ, Noh SH. Current practice of gastric cancer treatment. Chin Med J (Engl) 2014;127: 547-53.

21. Oh SJ, Hyung WJ, Li C, Song J, Kang W, Rha SY, et al. The effect of spleen-preserving lymphadenectomy on surgical outcomes of locally advanced proximal gastric cancer. J Surg Oncol 2009;99:275-80.

22. Lee KY, Noh SH, Hyung WJ, Lee JH, Lah KH, Choi SH, et al. Impact of splenectomy for lymph node dissection on long-term surgical outcome in gastric cancer. Ann Surg Oncol 2001;8:402-6.

23. Yu W, Choi GS, Chung HY. Randomized clinical trial of splenectomy versus splenic preservation in patients with proximal gastric cancer. Br J Surg 2006;93:559-63.

24. Sano T, Sasako M, Mizusawa J, Yamamoto S, Katai H, Yoshikawa T, et al. Randomized controlled trial to evaluate splenectomy in total gastrectomy for proximal gastric carcinoma. Ann Surg 2017;265: 277-83.

25. Kim YN, Aburahmah M, Hyung WJ, Noh SH. A simple method for tension-free Billroth I anastomosis after gastrectomy for gastric cancer. Transl Gastroenterol Hepatol 2017;2:51.

26. An JY, Yoon SH, Pak KH, Heo GU, Oh SJ, Hyung WJ, et al. A novel modification of double stapling technique in Billroth I anastomosis. J Surg Oncol 2009;100:518-9.

27. Noh SH, Yoo CH, Chung HC, Roh JK, Shin DW, Min JS. Early postoperative intraperitoneal chemotherapy with mitomycin C, 5-fluorouracil and cisplatin for advanced gastric cancer. Oncology 2001; 60:24-30.

28. Jeung HC, Rha SY, Jang WI, Noh SH, Chung HC. Treatment of advanced gastric cancer by palliative gastrectomy, cytoreductive therapy and postoperative intraperitoneal chemotherapy. Br J Surg 2002;89:460-6.

29. Cheong JH, Shen JY, Song CS, Hyung WJ, Shen JG, Choi SH, et al. Early postoperative intraperitoneal chemotherapy following cytoreductive surgery in patients with very advanced gastric cancer. Ann Surg Oncol 2007;14:61-8.

30. Kuramoto M, Shimada S, Ikeshima S, Matsuo A, Yagi Y, Matsuda $\mathrm{M}$, et al. Extensive intraoperative peritoneal lavage as a standard prophylactic strategy for peritoneal recurrence in patients with gastric carcinoma. Ann Surg 2009;250:242-6.

31. Nadiradze G, Giger-Pabst U, Zieren J, Strumberg D, Solass W, Reymond MA. Pressurized intraperitoneal aerosol chemotherapy 
(PIPAC) with low-dose cisplatin and doxorubicin in gastric peritoneal metastasis. J Gastrointest Surg 2016;20:367-73.

32. Lee JH, Hyung WJ, Noh SH. Comparison of gastric cancer surgery with versus without nasogastric decompression. Yonsei Med J 2002; 43:451-6.

33. Hyung WJ, Lee JH, Lah KH, Noh SH. Intraoperative needle decompression: a simple alternative to nasogastric decompression. J Surg Oncol 2001;77:277-9.

34. Hyung WJ, Song C, Cheong JH, Choi SH, Noh SH. Percutaneous needle decompression during laparoscopic gastric surgery: a simple alternative to nasogastric decompression. Yonsei Med J 2005;46:648-51.

35. Kim J, Lee J, Hyung WJ, Cheong JH, Chen J, Choi SH, et al. Gastric cancer surgery without drains: a prospective randomized trial. J Gastrointest Surg 2004;8:727-32.

36. Lee J, Choi YY, An JY, Seo SH, Kim DW, Seo YB, et al. Do all patients require prophylactic drainage after gastrectomy for gastric cancer? The experience of a high-volume center. Ann Surg Oncol 2015;22:3929-37.

37. Sasako M, Sano T, Yamamoto S, Kurokawa Y, Nashimoto A, Kurita A, et al. D2 lymphadenectomy alone or with para-aortic nodal dissection for gastric cancer. N Engl J Med 2008;359:453-62.

38. Songun I, Putter H, Kranenbarg EM, Sasako M, van de Velde CJ. Surgical treatment of gastric cancer: 15-year follow-up results of the randomised nationwide Dutch D1D2 trial. Lancet Oncol 2010; 11:439-49.

39. Wu CW, Hsiung CA, Lo SS, Hsieh MC, Chen JH, Li AF, et al. Nodal dissection for patients with gastric cancer: a randomised controlled trial. Lancet Oncol 2006;7:309-15.

40. Japanese Gastric Cancer Association. Japanese gastric cancer treatment guidelines 2014 (ver. 4). Gastric Cancer 2017;20:1-19.

41. Cunningham D, Chua YJ. East meets west in the treatment of gastric cancer. N Engl J Med 2007;357:1863-5.

42. Cunningham D, Allum WH, Stenning SP, Thompson JN, Van de Velde CJ, Nicolson M, et al. Perioperative chemotherapy versus surgery alone for resectable gastroesophageal cancer. N Engl J Med 2006;355:11-20.

43. Macdonald JS, Smalley SR, Benedetti J, Hundahl SA, Estes NC, Stemmermann GN, et al. Chemoradiotherapy after surgery compared with surgery alone for adenocarcinoma of the stomach or gastroesophageal junction. N Engl J Med 2001;345:725-30.

44. Bang YJ, Kim YW, Yang HK, Chung HC, Park YK, Lee KH, et al. Adjuvant capecitabine and oxaliplatin for gastric cancer after D2 gastrectomy (CLASSIC): a phase 3 open-label, randomised controlled trial. Lancet 2012;379:315-21.

45. Noh SH, Park SR, Yang HK, Chung HC, Chung IJ, Kim SW, et al. Adjuvant capecitabine plus oxaliplatin for gastric cancer after D2 gastrectomy (CLASSIC): 5-year follow-up of an open-label, randomised phase 3 trial. Lancet Oncol 2014;15:1389-96.

46. Ajani JA, Bentrem DJ, Besh S, D’Amico TA, Das P, Denlinger C, et al. Gastric cancer, version 2.2013: featured updates to the NCCN Guidelines. J Natl Compr Canc Netw 2013;11:531-46.

47. Waddell T, Verheij M, Allum W, Cunningham D, Cervantes A, Arnold D. Gastric cancer: ESMO-ESSO-ESTRO Clinical Practice Guidelines for diagnosis, treatment and follow-up. Ann Oncol 2013; 24 Suppl 6:vi57-63.
48. Ribic CM, Sargent DJ, Moore MJ, Thibodeau SN, French AJ, Goldberg RM, et al. Tumor microsatellite-instability status as a predictor of benefit from fluorouracil-based adjuvant chemotherapy for colon cancer. N Engl J Med 2003;349:247-57.

49. Network NCC. Clinical practice guidelines in oncology: colon cancer. 2016 [accessed on 2016 March 25]. Available at: http:// www.nccn.org/professionals/physician_gls/pdf/colon.pdf.

50. An JY, Kim H, Cheong JH, Hyung WJ, Kim H, Noh SH. Microsatellite instability in sporadic gastric cancer: its prognostic role and guidance for 5 -FU based chemotherapy after R0 resection. Int J Cancer 2012;131:505-11.

51. Kim SY, Choi YY, An JY, Shin HB, Jo A, Choi H, et al. The benefit of microsatellite instability is attenuated by chemotherapy in stage II and stage III gastric cancer: results from a large cohort with subgroup analyses. Int J Cancer 2015;137:819-25.

52. Smyth EC, Wotherspoon A, Peckitt C, Gonzalez D, Hulkki-Wilson S, Eltahir Z, et al. Mismatch repair deficiency, microsatellite instability, and survival: an exploratory analysis of the Medical Research Council Adjuvant Gastric Infusional Chemotherapy (MAGIC) trial. JAMA Oncol 2017;3:1197-203.

53. Choi YY, Cheong JH. To treat, or not to treat, that is the question: biomarker-guided adjuvant chemotherapy for stage II and III gastric cancer. Ann Surg 2018 Nov 22 [Epub]. Available at: https:// doi.org/10.1097/SLA.0000000000003102.

54. Guinney J, Dienstmann R, Wang X, de Reyniès A, Schlicker A, Soneson C, et al. The consensus molecular subtypes of colorectal cancer. Nat Med 2015;21:1350-6.

55. Sotiriou C, Pusztai L. Gene-expression signatures in breast cancer. N Engl J Med 2009;360:790-800.

56. Paik S, Shak S, Tang G, Kim C, Baker J, Cronin M, et al. A multigene assay to predict recurrence of tamoxifen-treated, node-negative breast cancer. N Engl J Med 2004;351:2817-26.

57. Sparano JA, Gray RJ, Makower DF, Pritchard KI, Albain KS, Hayes DF, et al. Adjuvant chemotherapy guided by a 21-gene expression assay in breast cancer. N Engl J Med 2018;379:111-21.

58. Cancer Genome Atlas Research Network. Comprehensive molecular characterization of gastric adenocarcinoma. Nature 2014; 513:202-9.

59. Tan IB, Ivanova T, Lim KH, Ong CW, Deng N, Lee J, et al. Intrinsic subtypes of gastric cancer, based on gene expression pattern, predict survival and respond differently to chemotherapy. Gastroenterology 2011;141:476-85.

60. Cristescu R, Lee J, Nebozhyn M, Kim KM, Ting JC, Wong SS, et al. Molecular analysis of gastric cancer identifies subtypes associated with distinct clinical outcomes. Nat Med 2015;21:449-56.

61. Gambardella V, Cervantes A. Precision medicine in the adjuvant treatment of gastric cancer. Lancet Oncol 2018;19:583-4.

62. Fujitani K, Yang HK, Mizusawa J, Kim YW, Terashima M, Han SU, et al. Gastrectomy plus chemotherapy versus chemotherapy alone for advanced gastric cancer with a single non-curable factor (REGATTA): a phase 3, randomised controlled trial. Lancet Oncol 2016;17:309-18.

63. Beom SH, Choi YY, Baek SE, Li SX, Lim JS, Son T, et al. Multidisciplinary treatment for patients with stage IV gastric cancer: the role of conversion surgery following chemotherapy. BMC Cancer 2018; 18:1116. 